\title{
The Virtual Metropolis
}

\author{
Mike Parsons \\ B. F.A. \\ Toronto, Ontario, Canada \\ hey apathy@hotmail.com
}

\section{INTRODUCTION}

"The Virtual Metropolis" is an interactive installation combining traditional ink drawings and stop motion animation with video game technology. The artwork features various intermingled imaginary environments including cityscapes, factory districts and war zones. The user is invited to explore these worlds, seamlessly moving from one area to next, to discover satirically iconic animations and imagery. Conceptually the work emphasizes the immediate connections each environment has with the others while using humorous vignettes to express discontent towards a virtual world not too dissimilar from our own.

\section{THE IMAGERY AND THE INTERFACE}

The artwork features an array of symbolic imagery. The metropolis is overrun by denizens and billboards (figure 1), the factories are repetitiously entrancing (figure 2) and the war zone is enveloped by skeletons, bombs, and faceless people falling from the sky. The installation is designed to challenge predominant consumerist ideologies by exploring the relationships which exist between man, technology, progress and the natural environment. The interface emphasizes the role of the individual by offering a unique interactive experience in which the user can explore and affect the artwork; a semiotic acknowledgment of the importance and potential behind the actions of anyone who chooses to get involved (Antonelli, P. (2011).

\subsection{THE MEDIUM AND THE MESSAGE}

Although there is much debate as to the effects that video games have users, many studies have shown that the content of the games has a greater influence than the medium itself. Violent games have been linked to aggressive behaviour (Bartholow, 2006) while problem-solving games have been successfully integrated into educational programs. The Quest to Learn Public School in

\author{
Michael Peters \\ B. Com., B. C.S. \\ Toronto, Onttario, Canada \\ redfivestandingby@gmail.com
}

New York City considers games a "central component in our daily lives and an important tool for intellectual exploration" (Corbett, 2010). The goal of the "Virtual Metropolis" is to amalgamate the video game platform with the philosophical content generally associated with fine arts in order to create an installation work simultaneously intellectually provocative as well as accessible to viewers of all ages.

\section{REFERENCES}

Antonelli, P. (2011) The MOMA Blog

http://www.moma.org/interactives/exhibitions/2011/t alktome/essay/ (retrieved 5 March 2012)

Bartholow, B.D. (2006) Chronic Violent Video Game Exposure and Desensitization to Violence: Behavioral and Event-Related Brain Potential Data, Journal of Experimental Social Psychology 42, no. 4 (2006): 532-539

Corbett, S. (2010) New York Times, http://www.nytimes.com/2010/09/19/magazine/19vi deo-t.html?pagewanted=all (retrieved 5 March 2012)

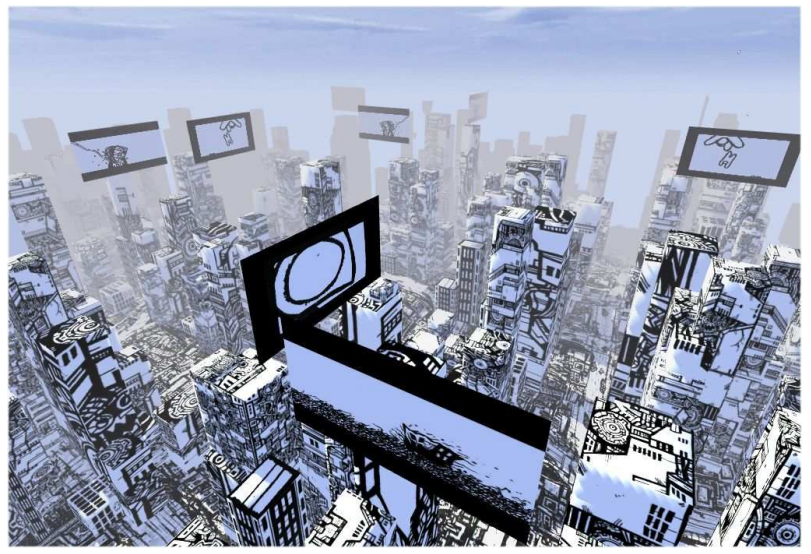

Figure 1: Virtual Cityscape Imagery "Flickering Lights of the Billboard Skyline" 


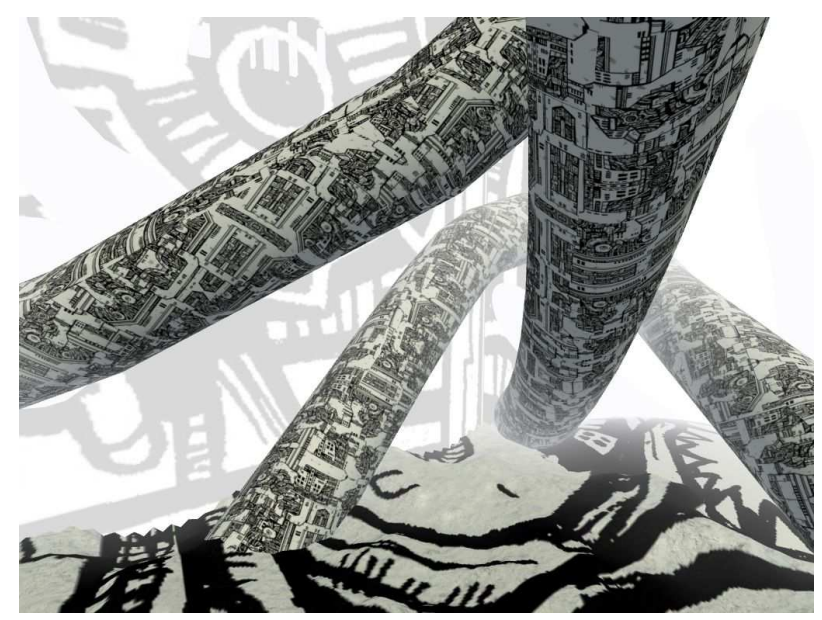

Figure 2: Factory District, "The intestinal track of mass consumption"

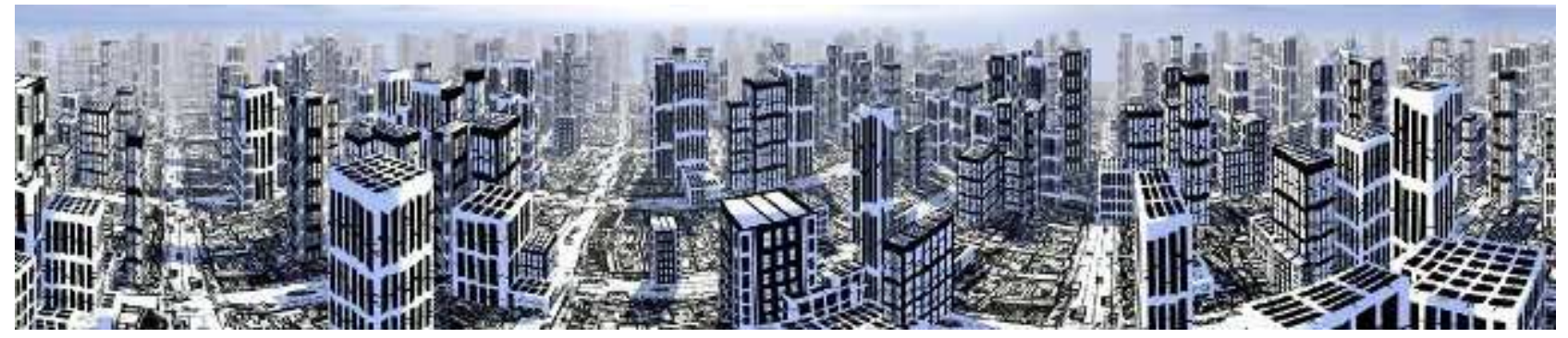

Figure 3: Landscape Panoramic intended for installation as a multi-screen and multiple user video projection 